GRAMSCI, Antonio. Concepção dialética da História. Rio de Janeiro: Civilização Brasileira, 1987.

PEREIRA Ruth da Cunha. Educação em serviço para o professor de CA a $4^{a}$ sèrie do Município do Rio de Janeiro: realidade e expectativas de participantes.
Rio de Janeiro, 1990. Tese (Doutorado) - UFRJ.

RIBEIRO, Darcy. O livro dos ClEPs. Rio de Janeiro: Bloch, 1986.

RIO DE JANEIRO. Secretaria Municipal de Educação do Rio de Janeiro. Regimento interno. Rio de Janeiro, 1987.

\title{
Levantamento e Catalogação de Fontes Primárias e Secundárias para o Estudo da História da Educação Brasileira e do Triângulo Mineiro e Alto Paranaíba
}

Pesquisadores: Wenceslau Gonçalves Neto, José Carlos Souza Araújo, Geraldo Inácio Filho e Décio Gatti Júnior

Instituição: Universidade Federal de Uberlândia (UFU) Fonte Financiadora: $\mathrm{CNPq}$

Este trabalho compartilha do levantamento de fontes primárias $\mathrm{e}$ secundárias da educação brasileira, realizado em diversos estados brasileiros, e inserido nas atividades do Grupo de Estudos e Pesquisas "História, Sociedade e Educação no Brasil", sediado na Faculdade de
Educação da Universidade Estadual de Campinas (Unicamp) e, por outro lado, subsidia atividades de pesquisa do Programa de Mestrado em Educação Brasileira da Universidade Federal de Uberlândia (UFU).

O grupo de trabalho de Uberlândia, constituído em 1993, 
constatou a necessidade de dinamizar a produção de estudos sobre a história da educação do Triângulo Mineiro e do Alto Paranaíba, onde se situa a UFU. Uma das hipóteses do grupo, para a carência de trabalhos nesta área, era de que faltava o conhecimento básico de dados relativos à educação regional: arquivos, bibliotecas, documentação escolar, coleções particulares etc. Portanto, a primeira preocupação foi com um levantamento de fontes, que pudesse embasar tais pesquisas.

Embora as microrregiões em estudo, situadas no extremo oeste do Estado de Minas Gerais, contem com mais de 50 cidades, esta pesquisa cobre apenas oito: Uberlândia, Araguari, Uberaba, Patos de Minas, Patrocínio, Araxá, Monte Carmelo e Ituiutaba. Isto se deve ao reconhecimento de sua importância histórica e/ou geoeconômica e ao fato de todas possuírem instituições de ensino superior, o que facilita contatos para a execução da pesquisa. Contudo, por razões de ordem financeira e operacional, os trabalhos vêm sendo conduzidos apenas nas duas primeiras microrregiões.

O projeto conta com financiamento do CNPq (recursos financeiros, seis bolsas de iniciação científica e uma de aperfeiçoamento) e com o apoio da UFU através do Centro de Documentação e Pesquisa em História (CDFHIS), onde o grupo de trabalho está sediado, o que tem permitido um certo aceleramento dos resultados.

Metodologicamente, observa-se o seguinte: a) identificação de arquivos para avaliação (dado o grande número de escolas recentes, numa primeira etapa será realizado o levantamento naquelas fundadas até a década de 60); b) seleção dos arquivos de interesse para a história da educação brasileira e regional; c) catalogação das fontes primárias e secundárias; d) registro e organização das informações catalogadas; e) publicação dos resultados da pesquisa através de um catálogo.

Em termos gerais, o levantamento já conta com mais de 6 mil fichas catalogadas, de diversos arquivos, discriminados abaixo. 
Uberlândia: Arquivo Público Municipal, $40^{\mathrm{a}}$ Superintendência Regional de Ensino, Arquivo Geral da Universidade Federal de Uberlândia, Escola Estadual de Uberlândia, Escola Estadual Born Jesus, Escola Estadual Cel. José Teófilo Carneiro, Biblioteca do Campus Santa Mônica da UFU, Escola Guarani, Colégio Nossa Senhora das Lágrimas, Escola Estadual Afonso Arinos, Instituto Irmã Teresa Valsé, Escola Estadual Dr. Duarte Pimentel de Ulhoa, Instituto Rio Branco, Biblioteca Pública Municipal, Escola Estadual Bueno Brandão e Colégio São José.

Araguari: Arquivo Público Municipal, Biblioteca Pública Municipal, Escola Estadual Raul Soares, Colégio Santa Terezinha e Colégio Sagrado Coração de Jesus.

Descritivamente, os documentos mais comumente encontrados são: acervo das bibliotecas (livros, livros didáticos, revistas pedagógicas, anais, boletins); livros de ata (aprovação escolar, ocorrências disciplinares, designação e posse, registro de matrícula, reu- niões administrativas, reuniões do colegiado, reuniões pedagógicas); documentação relativa à caixa escolar (repasse de gêneros alimentícios); calendários letivos; material de capacitação e treinamento de recursos humanos para o ensino; registros de contagem de tempo visando à aposentadoria; correspondências enviadas e recebidas (cartas, ofícios, convites, comunicações, memorandos, circulares); grades curriculares; livros de registro de freqüência escolar; processo de ampliação e mudanças físicas na rede escolar; estatutos e regimentos escolares; quadros de freqüência (folha de pagamento); recortes de jornal sobre legislação escolar (editais, resoluções, pareceres, portarias); inventários de maquinário e bens de utensílio; livros de ponto (controle de freqüência de professores e funcionários); pastas dos alunos (fichas cadastrais e históricos escolares); programas de ensino (planos de curso e de aula); registros contábeis (recibos de salário, FGTS, notas fiscais, balancetes, livros de contabi- 
lidade); registros escolares (estatísticas sobre matrícula, aprovação, abandono, transferência, admissão); termos de visita de inspeção e seus relatórios; requerimentos de transferência etc.

Quanto às condições gerais dos arquivos, a observação tem gerado algumas considerações, que apresentamos a seguir:

Espaço Físico - Não é adequado ao tamanho dos arquivos ou, às vezes, inexistente; observa-se, comumente, a existência de acervos espalhados pela secretaria, corredores, salas de diretoria etc. Os acervos, portanto, encontram-se espalhados (setorizados) por todo o prédio, nem sempre em função de uma organização burocrática, mas da ausência de espaço físico.

Organização - Há parte dos arquivos cujos documentos se encontram apenas amontoados no chão ou em prateleiras, porões, etc. A maneira como se guarda os documentos em geral é a corriqueira: em armários e prateleiras, em pastas AZ ou em pastas com elástico.
Recursos Humanos - Normalmente, as pessoas encarregadas dos arquivos não possuem formação adequada para cuidar dos mesmos.

Condições Ambientais Não há nenhum cuidado especial com as fontes. Há escolas, até, que guardam seus documentos em porões, sujeitos à umidade, ao mofo, à traça, ao cupim, enfim à deterioração. Existe, portanto, receio de que parte dos documentos não sobreviva por muito tempo.

A medida que avança a pesquisa, mais claras vão ficando as condições das fontes em Uberlândia e Araguari, o que aumenta a responsabilidade do grupo de trabalho. É necessário não apenas mapear a documentação mas, também, discutir formas de preservá-la, organizá-la e colocá-la à disposição do público. Em que pesem a boa vontade e a disposição de muitas direções e funcionários de escolas (e a presença de arquivos realmente organizados), grande parte da documentação encontra-se em situação precária. 